\title{
Investigation of the Diffusion Depth of Ni-Cu Thermal Spray Coating for the Low Carbon Steel
}

\author{
Aya N. Mohsin ${ }^{a^{*}}$, Hussain M. Yousif ${ }^{b}$, Sura S. Ahmed ${ }^{c}$ \\ a,c Materials Engineering Dept., University of Technology-Iraq, Alsina'a street, 10066 Baghdad, Iraq. \\ ${ }^{\text {b }}$ State Company for Steel Industries, Ministry of Industry and Minerals, Baghdad, Iraq. \\ *Corresponding author Email: mae.19.25@grad.uotechnology.edu.iq
}

\section{H I G H L I G H T S}

- Ni-Cu coatings were perfectly deposited on 52 low carbon steel by using the flame thermal sprayed method.

- Optical microscope showed that the experiment number six shows a homogeneous diffusion zone.

- X-ray diffraction (XRD) of the coating layer revealed $\mathrm{Cu}$ and $\mathrm{Ni}-\mathrm{Cu}$ phases which can acts as a protection barrier.

- SEM analyses informed that the coated sample has a homogeneous structure and covers all the substrate material.

\section{A R T I C L E I N F O}

Handling editor: Jawad K. Oleiwi

\author{
Keywords: \\ Flame thermal spraying \\ $\mathrm{Ni}-\mathrm{Cu}$ coating \\ Overlay diffusion depth
}

\begin{abstract}
A B S T R A C T
The effect of some parameters on the diffusion depth of the $\mathrm{Ni}-\mathrm{Cu}$ coating layer on 52 low carbon steel samples using flame thermal spraying was investigated. In this research, coating-powder particle $(1926.6 \mathrm{~nm})$ was used, spraying gases pressure $(0.5,1$ bar) for oxygen and acetylene was implemented, and the temperature of the sprayed coating layer on the substrate was in the range (500$750 \mathrm{C}^{\circ}$ ). Diffusion cross-section was observed by using an optical microscope. The microstructure and phase analysis of the coating layer was observed by using X-ray diffraction (XRD), and SEM respectively. At standoff distance was 125 $\mathrm{mm}$, powder feeding rate $30 \mathrm{~g} / \mathrm{min}$, substrate surface roughness $\mathrm{N} 10 \mu \mathrm{m}$, and the gun carrier transverse velocity $50 \mathrm{~mm} / \mathrm{m}$, the results showed high and homogeneous diffusion zone between the coating layer and the substrate (image 1f and $3 f$ ), however, image $2 \mathrm{f}$ exhibit the porosity in the boundary between the coating layer and the substrate.
\end{abstract}

\section{Introduction}

Thermal spraying is a group of coating processes that work on the deposited of melt or semi- melt or solid-state material on the other material surface. The coating material is spraying at high acceleration. The coating particles can permanently deform during a collision with the surface of the substrate and form the coating layer. Flame thermal spray is considered one of the earliest types of process spraying. The coating material may be used in powder or wires forms. The gases used to produce heat are usually oxygen and acetylene. The flare melts the coating material and is rapidly ejected to the substrate surface [1-3]

Overlay metallic coating is performed by applying new materials onto the surface of an element. By adding one or even more strong metallurgically connected layers with the base material that has: mechanical, metallurgy, and chemistry able of ensuring barrier properties against the influence of corrosion, erosion and, different phenomena caused by the service. The overlay is an effective and cost-saving method to change the exposed surface of the base metal, which has been selected to support the desired strength at the operating conditions [4-5].

Steel with a carbon content of less than $0.25 \%$ wt. is called low carbon steel. Mild steel is a remarkably low-price material, with good mechanical properties that are used for industrial, domestic, and petroleum applications. However, one of the major weaknesses of mild steel is its low corrosion resistance [4-7]. Because of their unique characteristics, Nickel-Copper alloys are extensively used as major engineering materials and most of these alloys show excellent corrosion resistance against a variety of severe conditions, such as seawater, acidic and alkaline corrosion media. $\mathrm{Ni}-\mathrm{Cu}$ alloys are commonly used in various applications, due to their good machinability, they are extremely thermally and electrically efficient. and particularly resistance to bio-fouling [6-9]. In this study, $\mathrm{Ni-Cu}$ alloy was used to coat low carbon steel for marine applications due to 
coating unique properties especially the pitting corrosion resistance (pitting the most common and insidious type of corrosion in the marine environment), and studying the effect of coating parameters (Standoff distance, Powder feeding rate, Substrate surface roughness, Gun carrier transverse velocity) on the structural and coating material's corrosion resistance [10-11].

\section{Experimental Procedure and Materials Used}

\subsection{Materials}

Samples of low carbon steel (St 52) according to DIN standard were machined to obtain surface roughness (N10, N8, and N6) using milling and grinding machines respectively. The chemical composition of the samples is illustrated in Table 1. Samples were cut with dimensions $(10 * 10 * 3 \mathrm{~mm})$ as shown in Figure 1 .

\subsection{Powder coating:}

$\mathrm{Ni}-\mathrm{Cu}$ binary alloy powder is used in the current research, with chemical composition and particle size $1926.6 \mathrm{~nm}$ are illustrated in Table 2 and Figure 2 respectively.

\subsection{Coating procedure:}

In this study, thermal spray coatings were achieved with an oxy-acetylene thermal spray gun mounted on a twodimensional table with a ball screw and drive system to allow the spray gun to move left and right smoothly. A flat table was used to place the work sample in the front of the spray gun. A ball screw with a drive system provides the sample holder, allowing it to move up and down. The distance between the spray gun and the sample surface was kept at $125 \mathrm{~mm}$, the powder feeder was set to $30 \mathrm{~g} / \mathrm{min}$, the Oxygen pressure was 0.5 bar while acetylene pressure was 1 bar, and the temperature of the sprayed coating layer on the substrate was (500-750 $\left.\mathrm{C}^{\circ}\right)$. All samples have a (1200-1400 $\left.\mu \mathrm{m}\right)$ coating thickness. The system of the thermal spray gun is shown in Figure 3 System of thermal spray was provided by a powder automatic feeder. Figure 4 shows the samples before and after coating.

To optimize data and results, the Taguchi method was utilized. The current study looked at four factors with three levels each as shown in Table 3.

X-ray diffraction analysis was used to identify the phase composition of the Ni-Cu coating layer by using (Shimadzu company/XRD 6000) at the Ministry of Science and Technology. The cross-section of the coating layer and substrate was accomplished by an optical microscope at the Ministry of Industry and Minerals. The SEM of the coated sample was carried out by (Inspect S 50) at the Applied science Department/ University of Technology.

Table 1: Chemical composition of St 52 samples

\begin{tabular}{lllllllllll}
\hline Elements & $\mathbf{C}$ & $\mathbf{S i}$ & $\mathbf{M ~ n}$ & $\mathbf{S}$ & $\mathbf{P}$ & $\mathbf{C r}$ & $\mathbf{N i}$ & $\mathbf{M o}$ & $\mathbf{C u}$ & $\mathbf{V}$ \\
\hline W t \% & 0.2 & 0.5 & $0.9-1.7$ & 0.03 & 0.025 & 0.5 & 0.5 & 0.08 & 0.3 & 0.1 \\
ASTM A572/A 572M- & 0.25 & 0.40 & 1.35 & 0.05 & 0.04 & 0.3 & 0.5 & 0.1 & 0.3 & $0.01-0.15$ \\
03a[12] & & & & & & & & & & \\
\hline
\end{tabular}

Table 2: $\quad$ Chemical composition of Ni-Cu powder

\begin{tabular}{lllllllllll}
\hline Elements & $\mathbf{N i}$ & $\mathbf{C u}$ & $\mathbf{S i}$ & $\mathbf{F e}$ & $\mathbf{A l}$ & $\mathbf{T i}$ & $\mathbf{C r}$ & $\mathbf{M o}$ & $\mathbf{C o}$ & $\mathbf{S}$ \\
\hline $\mathrm{Wt} \%$ & 40.525 & 30.085 & 4.159 & 0.437 & 0.277 & 0.064 & 0.064 & 0.046 & 0.026 & 0.1 \\
\hline
\end{tabular}

Table 3: Factors and their levels

\begin{tabular}{lccc}
\hline Factors & Level 1 & Level 2 & Level 3 \\
\hline Stand of distance (mm) & 100 & 125 & 150 \\
Powder feed rate (g/min.) & 10 & 20 & 30 \\
Substrate surface rough. (mic.) & $\mathrm{N} 10$ & $\mathrm{~N} 8$ & $\mathrm{~N} 6$ \\
Gun carrier tran. velocity (mm/min.) & 40 & 50 & 60 \\
\hline
\end{tabular}

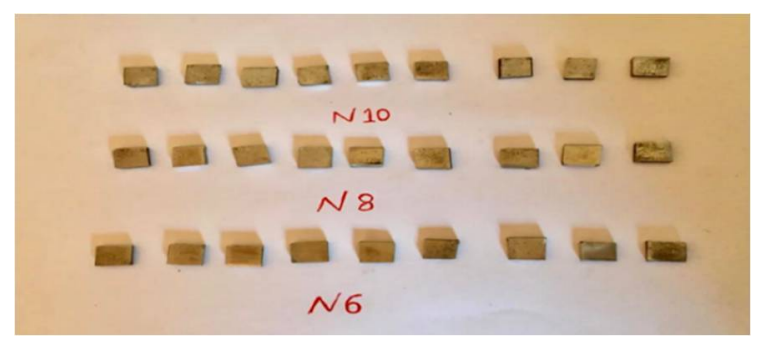

Figure 1: Low carbon steel (St 52) with surface roughness (N10, N8, and N6)

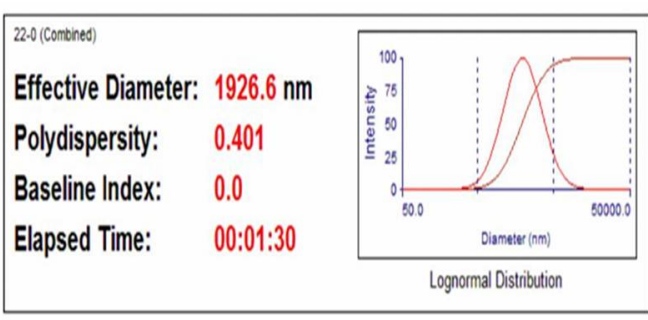

Figure 2: Particle size distribution of $\mathrm{Ni}-\mathrm{Cu}$ powder 


\section{Results and Discussion}

Taguchi method was used. Four factors with three levels were studied in the current study as shown in Table 4 . The substrate cross-section of the coating layer as represented in Figure 4 shows the diffusion depth between the substrate and the coating layer. Diffusion between the coating layer and the substrate may play an important role in the adhesion of the coating layer. For this purpose, a high-resolution optical microscope with the assistance of an image format program was used to display the diffusion depth as mentioned in Table 4. Three images represent trial one, trial two, and trial three for each experiment which illustrate the shape and size of the diffusion area as shown in Figure 5.

From which it has been shown that in experiment number one (image 1a, 2a, and 3a) the diffusion zone is narrow, and so is in experiment number two (image 1b, 2b, and 3b), four (image 1d, 2d, and 3d) and eight (image 1h, 2h, and 3h).

The images that represent experiment number three (1c, 2c, and $3 c)$ in which it appears extended into the substrate, The images that represent experiment number three appear extending into the metal, its extension in this way may cause residual thermal stresses in the substrate, and so is in the experiment number seven. Images representing experiment number five show porosity in the diffusion zone especially in trials one and two (image 1e and 2e), this may be related to the low powder feeding (20 g/ min.) and the compatibility of the powder feeding with the gun carrier transverse velocity. Experiment number six shows a homogeneous diffusion zone (image $1 \mathrm{f}$ and $3 \mathrm{f}$ ) and image $2 \mathrm{f}$ exhibits the porosity in the boundary between the layer of coating and the substrate. Experiment number nine exhibits a crack in the boundary between the layer of coating and the substrate (trial limage 1i), image $2 \mathrm{i}$ represents trial two a narrow and heterogeneous diffusion zone, while trial three (image $3 \mathrm{i}$ ) shows an extended diffusion zone.

\subsection{XRD result:}

The XRD pattern of the coating layer demonstrates two main phases, $\mathrm{Cu} / \mathrm{NiCu}$ and $\mathrm{NiCu}$ phases which behave as a protective barrier against the diffusion of unsafe kinds through the coating layer, therefore, decreasing the corrosion rate. The Ni may reduce the corrosion rate by forming Nickel oxide which acts as a protective film, as shown in Figure 6.

\subsection{SEM result:}

Substrate surface sample for the optimal conditions was examined using a Scanning electron microscope. The images exhibit the homogeneous coating layer which completely covers the substrate surface and the coating layer microstructure seems to be uniform and contentious and found to be rich in $\mathrm{Ni}-\mathrm{Cu}$ as shown in Figure 7.

Table 4: Taguchi orthogonal array matrix

\begin{tabular}{|c|c|c|c|c|c|c|c|c|}
\hline $\begin{array}{l}\text { Standoff } \\
\text { distance } \\
(\mathbf{m m})\end{array}$ & $\begin{array}{l}\text { Powder } \\
\text { feed rate } \\
\text { (g/min.) }\end{array}$ & $\begin{array}{l}\text { Substrate } \\
\text { surface } \\
\text { rough. (mic.) }\end{array}$ & $\begin{array}{l}\text { Gun carrier } \\
\text { tran. Velocity } \\
(\mathrm{mm} / \mathrm{min} .)\end{array}$ & Trail 1 & Trail 2 & Trail 3 & Mean & $\begin{array}{l}\mathrm{S} / \mathrm{N} \\
\text { ratio }\end{array}$ \\
\hline 100 & 10 & N10 & 40 & 166.560 & 167.120 & 166.871 & 166.871 & 44.437 \\
\hline 100 & 20 & N8 & 50 & 171.017 & 171.020 & 170.450 & 170.829 & 44.655 \\
\hline 100 & 30 & N6 & 60 & 189.782 & 190.561 & 193.170 & 191.171 & 45.623 \\
\hline 125 & 10 & N8 & 60 & 172.787 & 172.896 & 172.002 & 172.562 & 44.708 \\
\hline 125 & 20 & N6 & 40 & 194.407 & 195.861 & 196.530 & 195.599 & 45.815 \\
\hline 125 & 30 & N10 & 50 & 288.054 & 290.453 & 291.082 & 289.863 & 49.237 \\
\hline 150 & 10 & N6 & 50 & 190.840 & 189.694 & 186.709 & 189.081 & 44.370 \\
\hline 150 & 20 & N8 & 60 & 166.402 & 167.269 & 167.269 & 166.980 & 44.405 \\
\hline 150 & 30 & N10 & 40 & 169194 & 170.447 & 169.747 & 169.747 & 44.557 \\
\hline
\end{tabular}

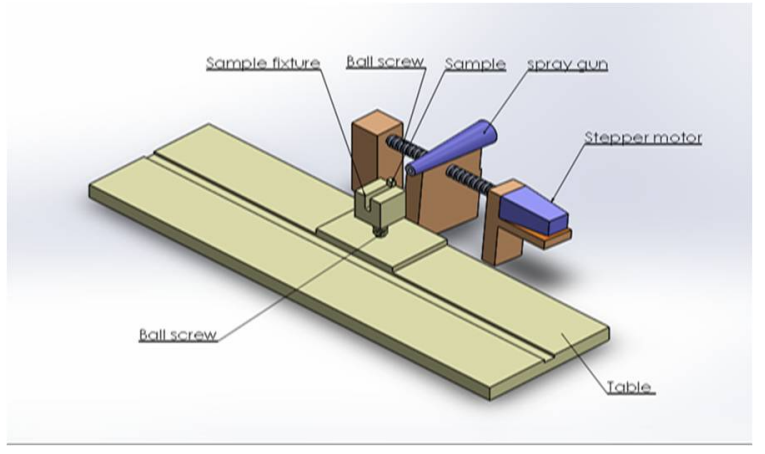

Figure 3: Thermal spraying system [13] 


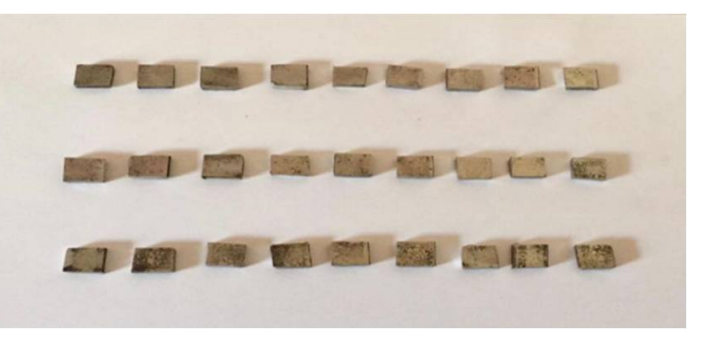

(A) Uncoated samples

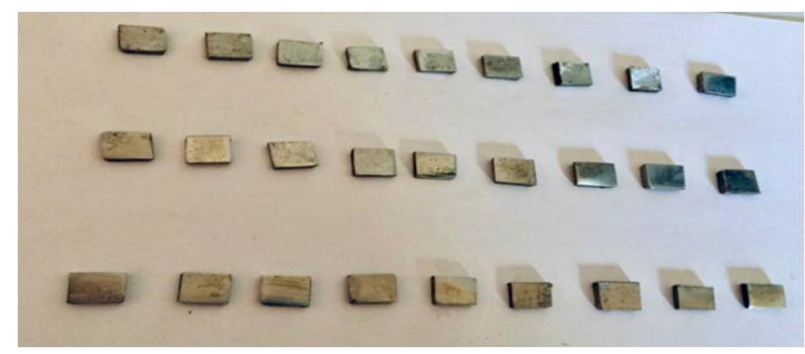

(B) Coated samples after surface machining Figure 4: Samples before and after coating

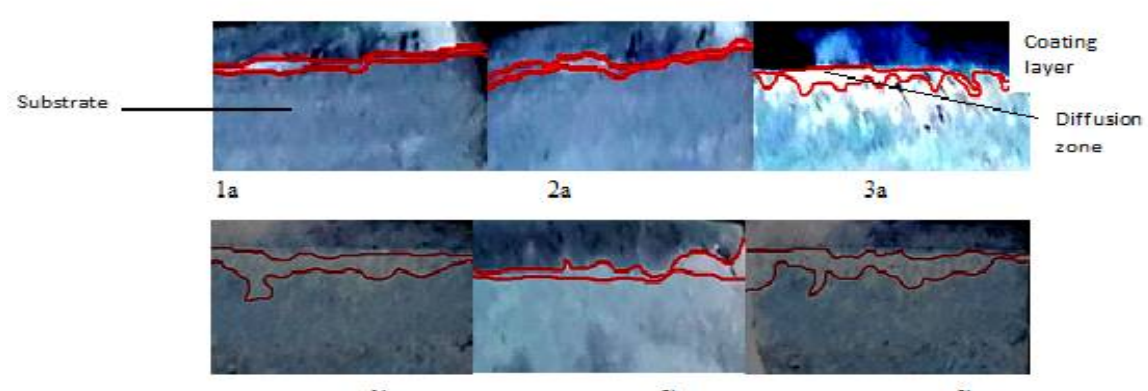

$\mathrm{zb}$

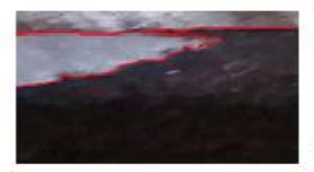

lc

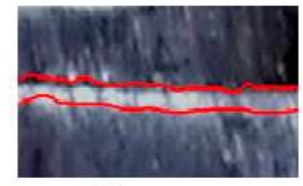

$1 \mathrm{~d}$

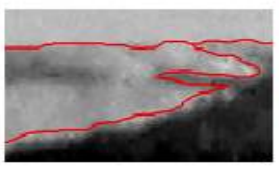

$2 c$

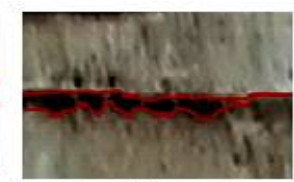

$2 d$

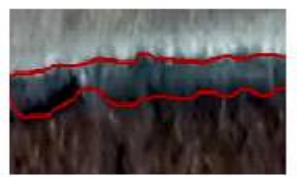

1e

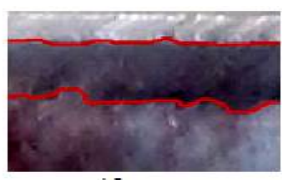

$1 \mathrm{f}$

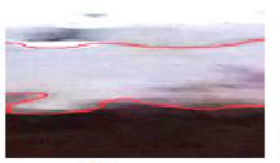

$1 \mathrm{~g}$

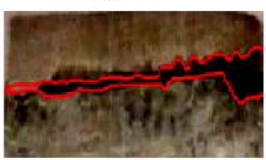

1h

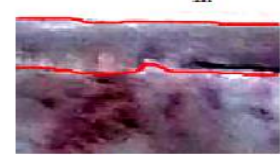

$1 \mathrm{i}$

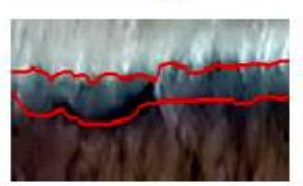

$2 \mathrm{e}$
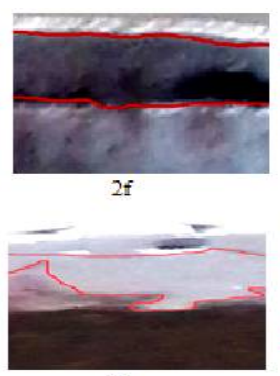

$2 \mathrm{~g}$

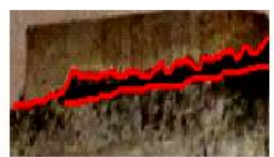

2h

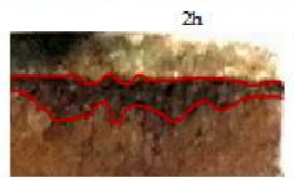

$2 \mathrm{i}$

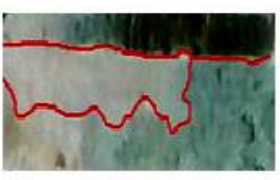

$3 c$

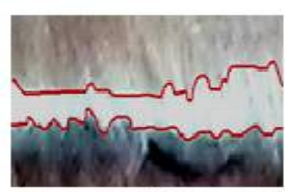

$3 d$

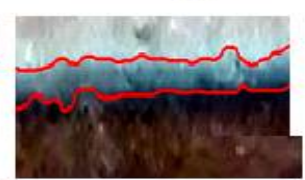

$3 e$
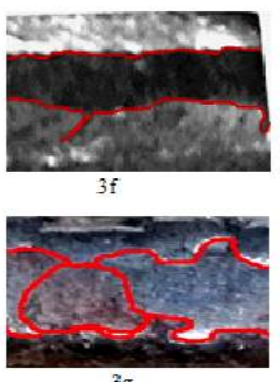

$3 \mathrm{~g}$
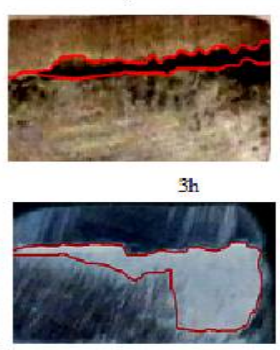

$3 \mathrm{i}$

Figure 5: Optical microscope diffusion images 10X magnification power 


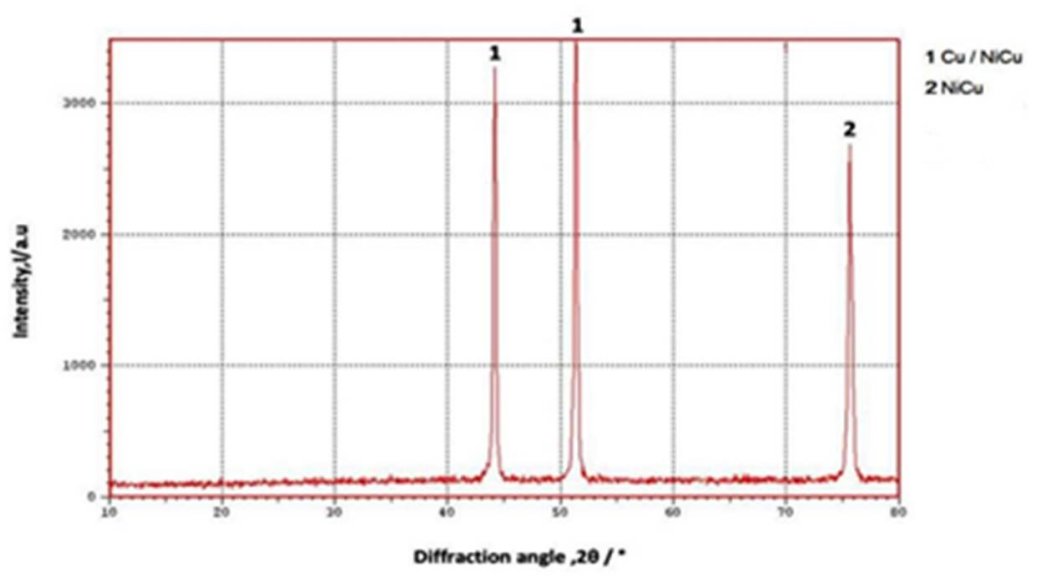

Figure 6: X-ray diffraction for the coating layer
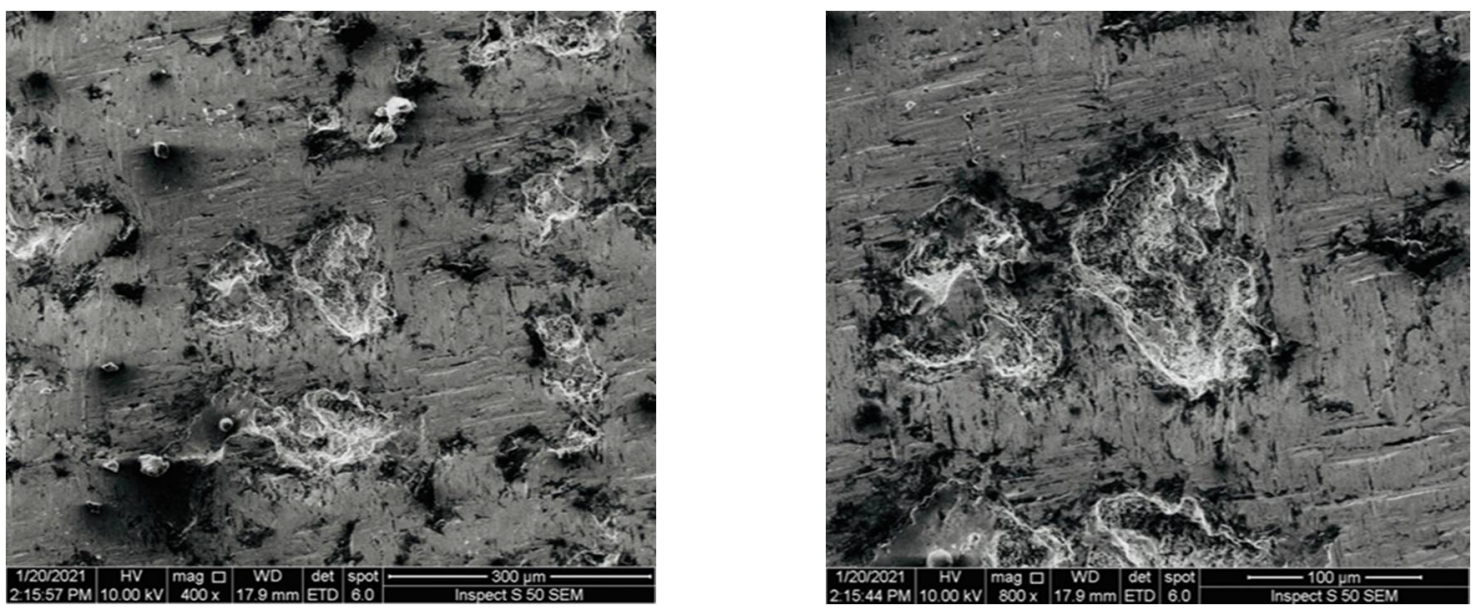

Figure 7: SEM image for coating layer

\section{Conclusion}

The Ni-Cu coatings were perfectly deposited on 52 low carbon steel by using the flame thermal sprayed method. The optical microscope showed that experiment number six shows a homogeneous diffusion zone (image if and $3 f$ ) and image $2 \mathrm{f}$ exhibits the porosity at the boundary between the layer of coating and the substrate. The X-ray diffraction (XRD) of the coating layer revealed $\mathrm{Cu} / \mathrm{NiCu}$ and $\mathrm{Ni}-\mathrm{Cu}$ phases which can act as a protective barrier against the unsafe kinds. SEM analyses informed that the coated sample has a homogeneous structure and covers all the substrate material.

\section{Author contribution}

All authors contributed equally to this work.

Funding

This research received no specific grant from any funding agency in the public, commercial, or not-for-profit sectors.

Data availability statement

The data that support the findings of this study are available on request from the corresponding author.

Conflicts of interest

The authors declare that there is no conflict of interest.

\section{References}

[1] L. Pawlowski, The science and engineering of thermal spray coatings, John wiley \& sons, 2nd Edition, Chichester, (2008).

[2] G. J. Matrood, A. M. Al-Gaban, H. M. Yousif, Studying the erosion corrosion behavior of NiCrAlYcoating layer applied on AISI 446 stainless steel using thermal spray technique, Eng. Technol. J., 38 (2020) 1676-1683. https://doi.org/10.30684/etj.v38i11A.1691

[3] M. A. Habeeb, M. J. Kadhim, F. A. Hashim, M. A. Bash, Effect of laser treatment on the surface roughness of multilayer plasma sprayed thermal barrier coating system, Eng. Technol. J., 39 (2021) 180-188. https://doi.org/10.30684/etj.v39i2A.1570

[4] A. Singh, V. Chawla, A. Singh, Combating hot corrosion of boiler tubes with detonation gun sprayed coatings : a Review, 5762 (2013) 742-749. 
[5] A. Volpi , G. Serra, Weld overlay of highly corrosion resistant nickel chromium Molybdenum Alloys, UNS N06059, on Low Alloy Equipment Operating at High Temperature, ASME, Symp. Elev. Temp. Appl. Mater. Foss. Nucl. Petrochemical Ind., (2018) 1-12. https://doi.org/10.1115/ETAM2018-6715

[6] M. A. Abdulrazzaq , Z. D. Kadhim, Protection low carbon steel from corrosion, J. Eng. Sust. Develo., 24 (2020) 58-66. https://doi.org/10.31272/jeasd.24.3.4

[7] M. H. Z. Mohd, Y. Mohd, N. N. C. Isa, Cu-Ni alloys coatings for corrosion protection on mild steel In $0.5 \mathrm{M} \mathrm{NaCl}$ solution, Sci. Lett., 11 (2017).

[8] A. K. Hussein, L. K. Abbas, J. J. Dawood, N. J. Ismae, Modeling of carburization parameters process for low carbon steel, Eng. Tech. J., 34 (2016) 1069-1079.

[9] M. K. A. Alsaadi, Bending characteristics of carburized low carbon steel experimental and bending characteristics of carburized low carbon steel experimental and numerically study, J. Univ. Babylon. eng. sci., 25 (2017) 761-773.

[10] W. Shaohua, G. Xingwu, Y. Haiyan, D. Jichun, Z. Rongyu G. Jia, P. Liming, D. Wenjiang., Electrodeposition mechanism and characterization of Ni-Cu alloy coatings from a eutectic-based ionic liquid, Appl. Surf. Sci., 288 (2014) 530-536. https://doi.org/10.1016/j.apsusc.2013.10.065

[11] N. Rajasekaran, S. Mohan, Structure, microstructure and corrosion properties of brush-plated Cu-Ni alloy, J. Appl. Electrochem., 39 (2009) 1911-1916. https://doi.org/10.1007/s10800-009-9899-X

[12] J. E. Bringas, Handbook of comparative world steel standards, ASTM Data Series, 3rd edition, USA, (2004).

[13] A. S. Fakhri, A. M. Al-Gaban, H. M. Yousif, Improving Oxidation Resistance Wear Properties of Valves Trays Used in Oil Distillation Towers, J. Phys. Conf. Ser., 1279 (2019). https://doi.org/10.1088/1742-6596/1279/1/012015 